\title{
OCCURRENCE OF ASBESTOS-RELATED OCCUPATIONAL DISEASES IN THE CZECH REPUBLIC IN THE LAST 20 YEARS
}

\author{
Magdaléna Janošíková ${ }^{1,2}$, Marie Nakládalová ${ }^{1,2}$, Ladislav Štěpánek ${ }^{1,2}$, Alena Boriková1, ${ }^{1}$, Helena Vildová2, Matyáš \\ Fošum ${ }^{1,3}$ \\ 1'Department of Occupational Medicine, Faculty of Medicine and Dentistry, Palacký University Olomouc, Olomouc, Czech Republic \\ 2Department of Occupational Medicine, University Hospital Olomouc, Olomouc, Czech Republic \\ ${ }^{3}$ Ministry of Health, Prague, Czech Republic
}

\section{SUMMARY}

Objectives: Asbestos-related diseases are still a current problem worldwide. What is their occurrence in the Czech Republic? The answer is the subject of this study, which aims to provide a general and regional overview of the situation over the last 20 years with a more detailed focus on mesothelioma, the development of which is highly associated with asbestos exposure and the issue of their recognition as an occupational disease.

Methods: In its retrospective reviews, the study is based on analyses of data from the Institute of Health Information and Statistics of the Czech Republic and data from the Czech National Cancer Registry, which also interconnects.

Results: In the last 20 years, 512 new cases of occupational diseases from asbestos have been reported, namely 228 cases of pleural thickening, 133 mesotheliomas, 92 asbestoses, and 59 cases of lung cancer. In the last 5 years, mesotheliomas $(n=39)$ predominated among the reported diseases with a $45 \%$ proportion in the total number of 86 cases. The trend in their incidence, as the only one among asbestos-related diseases, is not declining. There was a significant difference in the overall incidence of mesothelioma in a general population and the incidence of occupational mesotheliomas. At the national level, occupational aetiology was acknowledged in only $11.3 \%$ of cases of mesothelioma on average. The highest proportion of occupational mesotheliomas and the highest incidence of all asbestos-related diseases were found in regions where the largest asbestos processing plants were located.

Conclusion: The authors emphasize the importance of work history for the diagnostic process of asbestos-related diseases and also the need to perform follow-up examinations for their early detection.

Key words: asbestos-related disease, malignant mesothelioma, incidence, occupational disease

Address for correspondence: M. Janošíková, Department of Occupational Medicine, Faculty of Medicine and Dentistry, Palacký University Olomouc and University Hospital Olomouc, Hnèvotínská 976/3, 77515 Olomouc, Czech Republic. E-mail: magdalena.janosikova@fnol.cz

https://doi.org/10.21101/cejph.a6297

\section{INTRODUCTION}

Although asbestos is outstanding in its properties, such as fire resistance and resistance to acids and alkalis, and insulating properties which are highly useful in industry, especially the construction industry, asbestos fibres inhalation significantly increases the risk of developing asbestos-related diseases. Asbestos exposure is associated with an increased risk of developing malignancies such as malignant mesothelioma, cancer of the lung, larynx, and ovaries, as well as the development of non-malignant diseases such as asbestosis, pleural thickening or benign asbestos pleural effusion (1). According to the International Agency for Research on Cancer (IARC) and the International Labour Organization (ILO) asbestos is classified in all its forms, including chrysotile, to Group 1 carcinogens, in other words, to proven human carcinogens $(2,3)$, and it is also the most important factor in the development of malignant occupational diseases (ODs) (4). Its danger lies in, among other things, a non-threshold effect and a decades-long latent period (5). In this context, the latest available estimates by the WHO, which assume that 125 million people worldwide are occupationally exposed to asbestos (1), cannot be reassured, and moreover, over 220,000 of them die annually from asbestos dust (4). Therefore, asbestos processing has been banned in over 60 countries (6). However, despite apparent health risks, asbestos mining continues in some countries, notably Russia, China, Brazil, or Kazakhstan (7).

Among the malignant diseases, a very serious disease - malignant mesothelioma - is noted for its close link to the previous asbestos exposure. It is reported that up to $90 \%$ of cases are associated with asbestos exposure $(8,9)$, mainly in pleural localization (9). The link is more pronounced than in other types of asbestos malignant diseases, therefore, in case of malignant mesothelioma, current signs of asbestosis or pleural thickening are not required to be recognized as an occupational disease in the Czech Republic, unlike in case of lung, laryngeal or ovarian cancer. Other aetiological factors of mesothelioma include, in addition to asbestos exposure, which may also be of a non-professional origin, inhala- 
tion of alternative persistent mineral fibres, radiation exposure, or an inherited genetic mutation $(9,10)$.

In case of the development of a disease in association with professional asbestos exposure, we may consider the recognition of OD. In the Czech Republic, the conditions for the recognition of OD are legally stipulated and include the detection of the disease listed among items in the valid List of Occupational Diseases (LODs) - with specific clinical criteria - and verification of hazardous exposure to asbestos dust in the working environment by the public health authority (hygienic examination) (11).

In the Czech Republic, asbestosis, pleural thickening, mesothelioma, lung, laryngeal and ovarian cancers are currently recognized as ODs. The consequences of some asbestos-related diseases in the Czech Republic began to be investigated only in the 1990s, and the conditions for the recognition of these diseases as ODs have also changed over the years in the legislative area. However, asbestosis has been recognized since 1947 if "typical X-ray features" are present or associated with lung cancer. Since 1995, the condition of typical X-ray features has been specified in the LODs as an assessment according to the ILO classification with a frequency of signs s $2 / 2, \mathrm{t} 2 / 2, \mathrm{u} 2 / 2$ and higher. These conditions are valid until these days. Pleural thickening and mesothelioma were not included separately in the LODs until 1995. The condition for the recognition of pleural thickening as an OD was the demonstration of a pulmonary function disorder, which has been more narrowly specified as a restriction-type ventilation disorder since 2011. Lung cancer has always been recognized only in conjunction with pleural thickening or asbestosis (specifically defined from 2011 onwards with a frequency of signs $\mathrm{s} 1 / 1, \mathrm{t} 1 / 1, \mathrm{u} 1 / 1$ according to ILO classification). Laryngeal cancer was included into the LODs in 2011 and ovarian cancer only in 2014. Both conditions are recognized in the same recognition conditions as lung cancer, i.e. they could only be recognized in conjunction with pleural thickening or asbestosis, from the frequency of signs $\mathrm{s} 1 / 1$, $\mathrm{t} 1 / 1, \mathrm{u} 1 / 1$ according to ILO classification (11-14).

The importance of the issue of asbestos-related diseases is demonstrated, inter alia, by the WHO's call for creating national asbestos profiles as tools to estimate asbestos exposure. A key part of the asbestos profile is the mapping of past and present risks (15). Accordingly, the intention of this study is to describe the occurrence of asbestos-related ODs in the Czech Republic, both in general and regional terms, over the past 20 years. We also aimed to compare the incidence of mesothelioma cases recognized as ODs with those in the general population.

\section{MATERIALS AND METHODS}

Due to its character, the study ranks among retrospective descriptive-analytical studies. The survey of asbestos-related ODs in the last 20 years was based on an analysis of data collected by the Institute of Health Information and Statistics of the Czech Republic (IHIS) available in the Czech National Registry of Occupational Diseases (CNROD) of the National Institute of Public Health (16). The analysis consisted in data collecting, summaries making, and drawing conclusions.

The survey of mesothelioma incidence in the population is based on data from the Czech National Cancer Registry
(CNCR), which is also administered by IHIS. Data are drawn mainly from CNCR publications and surveys and analyses of the SVOD web portal $(17,18)$. The prevalence of all mesotheliomas in the population, according to CNCR data, was then linked to data on the number of reported cases of occupational mesotheliomas available from CNROD data (16) to determine the proportion of occupational mesotheliomas in population. The data analysis was based on data collecting, averaging, and expressing as a percentage.

The periods were chosen according to the intersection of the availability of data from both databases and taking into account their consistency in the matter of territorial administrative division.

\section{RESULTS}

In the last 20 years, 512 new cases of ODs from asbestos have been reported, including 92 asbestoses, 228 cases of pleural thickening, 133 mesotheliomas, and 59 cases of lung cancer (Fig. 1). The conditions for the recognition of OD from asbestos remained unchanged throughout the period, except for pleural thickening, which, as already mentioned, have been tightened since 2011, when the condition of concomitant pulmonary dysfunction was limited to restriction-type ventilation disorder.

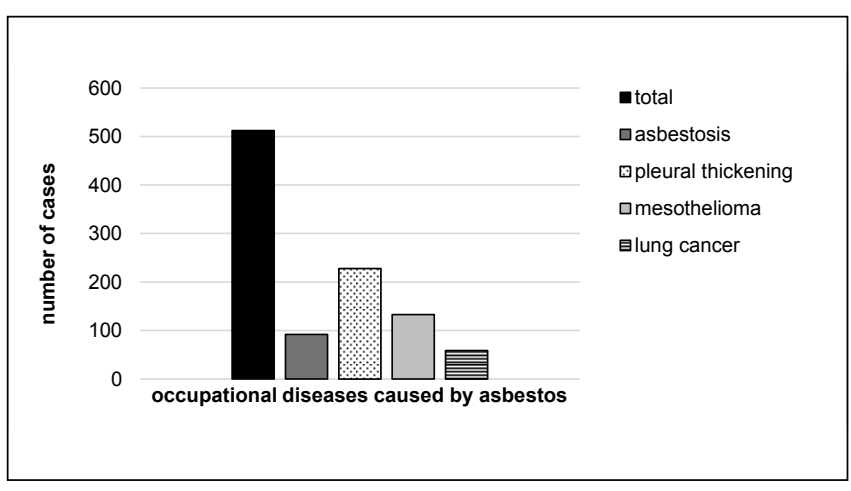

Fig. 1. Occurrence of occupational diseases caused by asbestos in the Czech Republic in the last 20 years.

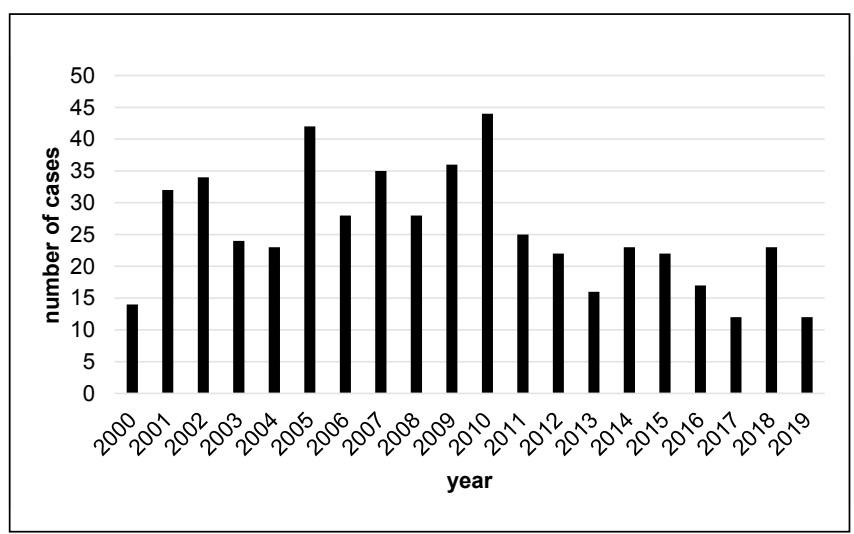

Fig. 2. Incidence of occupational diseases caused by asbestos in the Czech Republic. 
The total number of cases of ODs caused by asbestos in individual years of the observed period 2000-2019 does not show any clear trend (Fig. 2). However, trends are already evident in particular diseases. The trend is declining for non-malignant diseases and lung cancer, while for mesothelioma it is increasing, as shown in Figure 3, which also shows that mesothelioma has dominated the reported ODs in the last 5 years, accounting for almost half cases $(45.4 \%)$, of them with 39 newly reported cases of ODs caused by asbestos, which were recorded in the last 5 years of the observed period in a total number of 86 . Specifically, 8 cases of mesothelioma were reported in 2015, 11 in 2016, 7 in 2017, 11 in 2018, and 2 cases in 2019.
Surveys on the incidence of ODs from asbestos at the level of individual regions of the Czech Republic in the period 2001-2019, chosen for its consistency in territorial administration, show that the highest number of new cases of all ODs from asbestos was in the Central Bohemian Region $(n=284)$, followed by the Olomouc Region $(\mathrm{n}=102)$ and the Hradec Králové Region $(\mathrm{n}=69)$ (Fig. 4). Regarding individual diseases from asbestos, the Central Bohemian Region dominates in the occurrence of asbestoses $(\mathrm{n}=55)$, pleural thickening $(\mathrm{n}=165)$, and lung cancers $(\mathrm{n}=25)$. The number of cases of recognized mesotheliomas in the observed period in the Central Bohemian Region was 39. In the Olomouc Region, the distribution was as follows: 6 asbestoses, 28 cases of

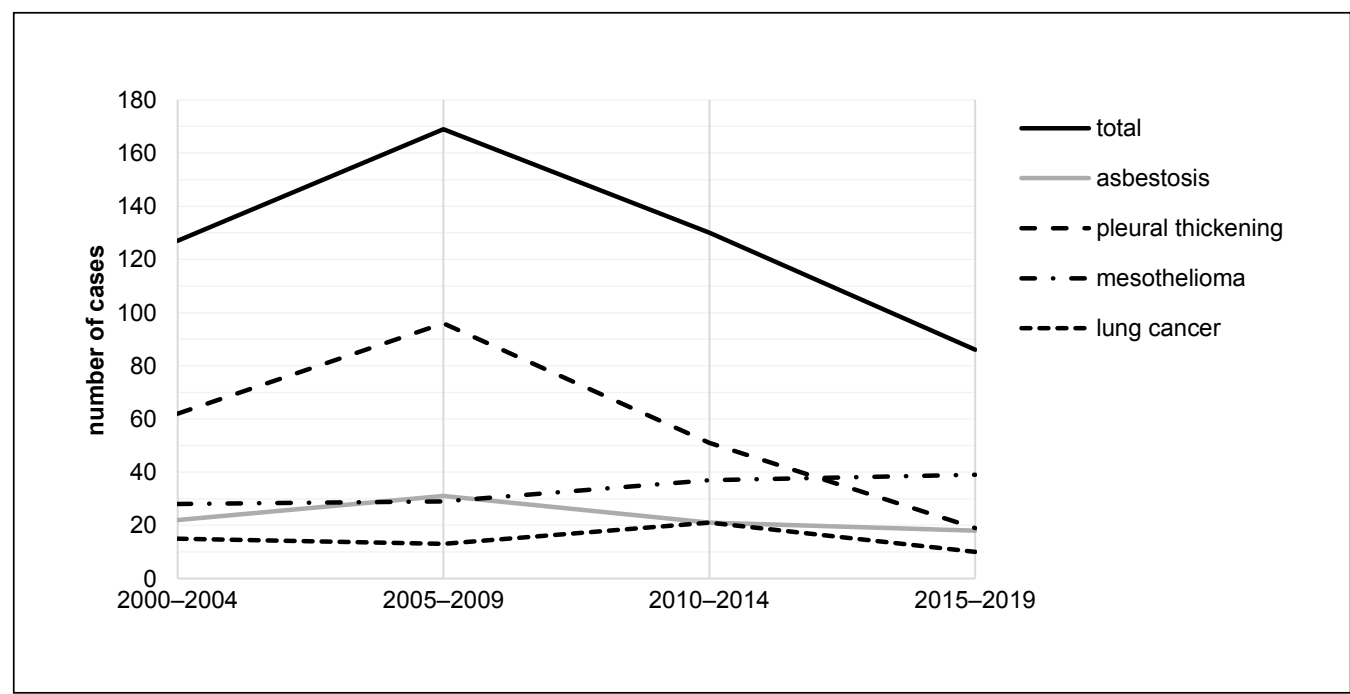

Fig. 3. Trends in incidence of occupational diseases caused by asbestos in the Czech Republic.

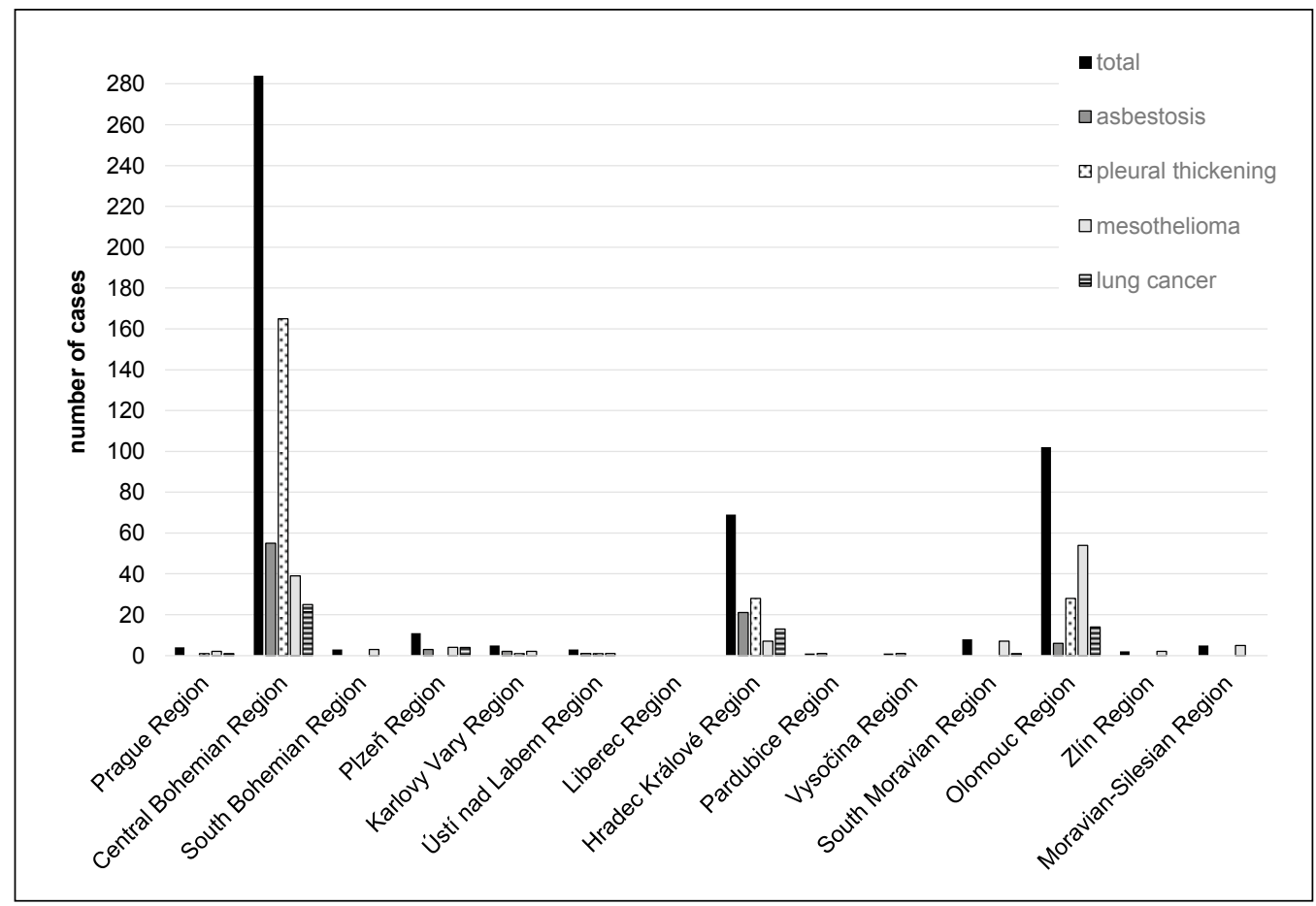

Fig. 4. Summary of new cases of occupational diseases caused by asbestos in regions (2001-2019). 


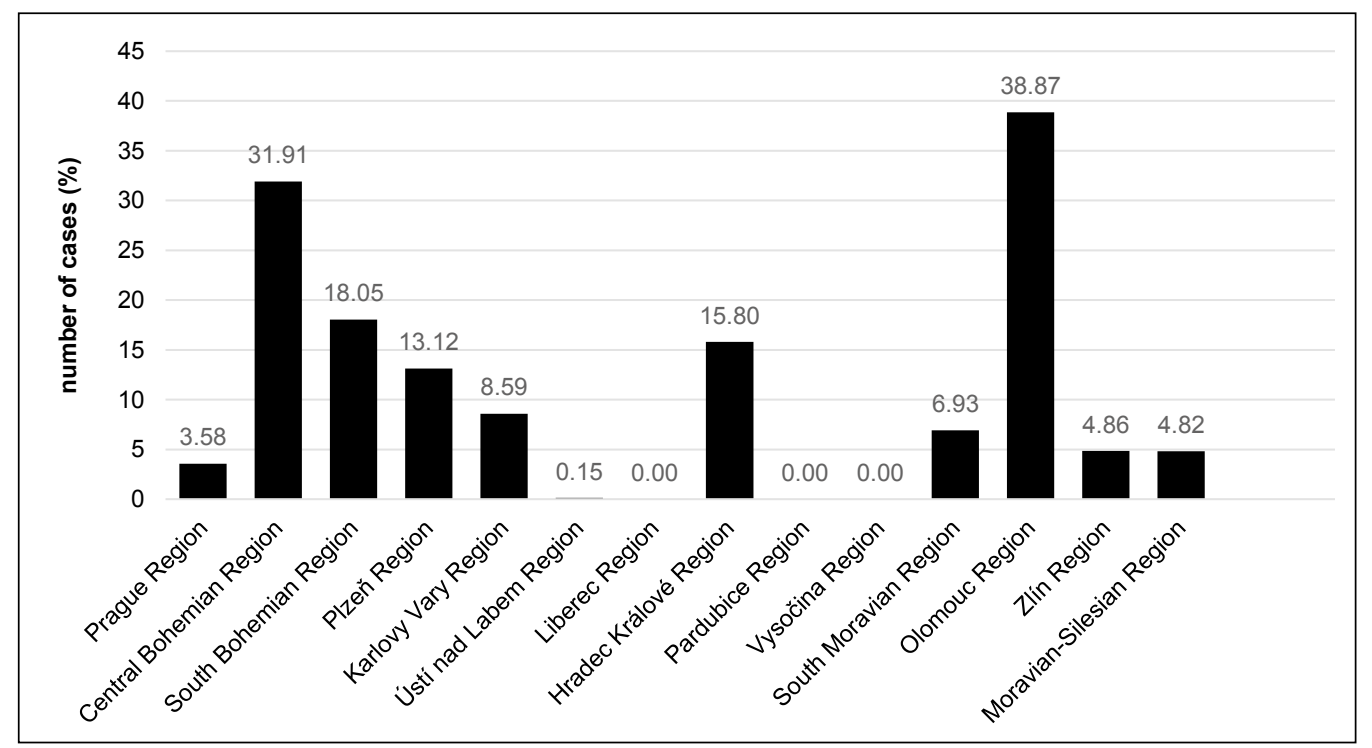

Fig. 5. Average percentage of occupational mesotheliomas in their total number (2001-2017).

pleural thickening, 14 carcinomas, and 54 mesotheliomas. The Olomouc Region is, therefore, a region with the highest incidence of occupational mesothelioma. The number of 54 cases represents $42.9 \%$ of the nationwide number of reported cases of occupational mesothelioma $(\mathrm{n}=126)$.

The Olomouc Region is also the leader in the occurrence of all new cases of mesothelioma in the population. In the period 2001-2017, the average incidence was 1.3 cases per 100,000 population per year (with a range of values from 0.47 in 2013 to 2.04 in 2012). The national average incidence of mesothelioma in the same period was 0.5 cases per 100,000 population per year (with a gender distinction -0.64 cases in men and 0.37 cases in women). The period 2001-2017 was chosen due to the consistency of the territorial administrative division of the state and the availability of CNCR data.

Besides, the proportion of occupational mesotheliomas in the total number of reported cases in the population according to CNCR was the highest in the Olomouc Region in the period, (38.9\%) (Fig. 5). In the same period, occupational aetiology was attributed to only $11.3 \%$ of cases of mesothelioma nationwide, on average.

\section{DISCUSSION}

The evaluated data highlights the fact that although many countries, including the Czech Republic, have implemented protective restrictive measures against asbestos processing, we still encounter new diseases caused by asbestos. The trend of their occurrence, except for malignant mesothelioma, is already declining in the Czech Republic. The same conclusions were reached by the national epidemiological study of Poland focused on the analysis of the incidence of asbestos-related diseases between the years 1970-2015 (19).

An important finding of our analysis lies in the increase in the number of new cases of occupational mesothelioma in recent years. Despite the long time lag, the numbers are not decreasing yet. Similarly focused studies using the data collected by the CNROD, established in 1991 at the National Institute of Public Health in Prague, have ascertained that the annual numbers of recognized tumours (mesotheliomas and lung cancers) have increased from 6.33 per year using data from 1991-2005 (20) to 7.15 per year based on data from 1991-2009 (21) to 9.60 per year in the past 20 years. The proportion of mesotheliomas among malignant tumours slightly increased from 53.6\% (1991-2005) to $63.3 \%$ according to recent data.

However, trends in the incidence of mesothelioma vary across European countries. While, for example, Germany has already seen a steady decline (22), in other countries, such as Greece, the trend of incidence is still rising (23). A possible explanation for the different incidence of mesothelioma across Europe may be the inconsistent implementation of asbestos processing bans in combination with the extremely long latency of mesothelioma, which on average exceeds 40 years (24-26).

However, the incidence of mesothelioma in the Czech population is low compared to other European countries. In the period 2001-2017, the incidence reached 0.5 cases per 100,000 population per year, with a gender distinction of 0.64 cases in men and 0.37 cases in women. While the aggregate values for both sexes and men individually are significantly lower than for other European countries, for women the incidence is comparable to Germany and the Scandinavian countries (22). The reason for the relatively low incidence of mesothelioma in the Czech population may be the fact that asbestos was not mined on the territory of the present Czech Republic but only processed.

The regional stratification of recognized asbestos OD corresponds to the location of the plants on the map that have processed asbestos in the past. The highest occurrence of malignant mesotheliomas in the Olomouc Region can be explained by the fact that one of the plants also processed blue asbestos (crocidolite), which has a higher malignant potential than white asbestos (chrysotile) (27) processed mostly in other plants in the country. 
From an occupational medicine point of view, it is significant that the proportion of cases of mesothelioma recognized as an OD in the total number of all mesotheliomas in the population appears to be very low $(11.3 \%)$. As a reason for the low proportion, the possibility of underestimating the occupational aetiology offers, especially if the often mentioned $90 \%$ aetiological connection of mesothelioma with asbestos exposure is considered $(7,8)$. The findings of a study by the Italian Mesothelioma Registry (ReNaM) and the Regional Operations Centre (COR), which analysed retrograde verification of occupational asbestos exposure in malignant mesothelioma cases using a structured questionnaire, also found occupational asbestos exposure in $67 \%$ of mesothelioma cases (28). This conclusion is also supported by other studies previously conducted in the Czech Republic dealing with the incidence of occupational mesothelioma and occupational cancers in general $(20,21)$.

The proportion of occupational mesothelioma varied significantly between regions, a logically higher proportion of occupational mesothelioma was found in regions that had asbestos processing plants on their territory in the past. More effective recognition of mesothelioma as an OD can also be expected in these regions. This is also related to the more consistent detection of people previously exposed to asbestos with the implementation of follow-up examinations, which enables earlier diagnosis as well as a better prognosis and also the possibility of fair compensation to afflicted individuals.

A significant problem in assessing occupational aetiology is, especially due to the long latent period, the occasional but with increasing years more frequent inability to objectively verify the exposure to asbestos by hygienic examination. Mesothelioma is rarely recognized as an OD even in cases where work with asbestos was usually only a small part of the work. These are mainly manual professions, whose work included, for example, cutting and application of insulating material containing asbestos, the profession of electrician, car mechanic or boiler repairman, who came into contact with asbestos during repairs and maintenance. A thorough work history of diseases with a possible link to asbestos is, therefore, important. It is also worth mentioning that laryngeal cancer and ovarian cancer have not yet been recognized in the Czech Republic as an OD, probably since these diseases have only recently been included in the LODs in the Czech Republic.

The issue of asbestos-related diseases is highly important and still needs to be addressed and taken into account not only in previously exposed people but also in those currently exposed. Occupational exposure to asbestos dust can still be relevant, for example in the repair and demolition of buildings or mining and processing of aggregates. In medical practice, it is necessary to consistently perform preventive examinations of these workers and focus on work history to rectify the insufficient recognition and compensation of asbestos-induced tumours and asbestosrelated diseases in general, especially mesothelioma, a signalling tumour for asbestos. This also applies to other occupational tumours.

Last but not least, it is also important to inform both professionals and the general public about asbestos-related diseases. Especially asbestos-induced malignancies should be remembered, as asbestos still occurs in our environment.

\section{CONCLUSIONS}

Unlike other asbestos-related ODs, the incidence of occupational malignant mesotheliomas in the Czech Republic does not appear to have a persuasive declining trend yet. Most cases of asbestos-related ODs are reported in regions where asbestos was processed in the second half of the 20th century. The proportion of occupational malignant mesotheliomas in all cases of the disease in the general population for the period 2001-2017 is only $11.3 \%$ on average.

This topic is highly important, because of the underestimation of the recognition and compensation of asbestos-induced tumours, especially mesothelioma. Asbestos-induced malignancies should be remembered both by professionals and the general public, as asbestos still occurs in our environment. Czech data for asbestosinduced cancer represent a tip of the iceberg, and some types of occupational cancers due to asbestos (laryngeal cancer, ovarian cancer) have not yet been recognized in this country. Widespread implementation of prevention strategies to reduce the occurrence of asbestos-related diseases should become one of the priorities of the national health policy.

\section{Acknowledgements}

The work was supported by IGA LF 2020 (IGA_LF_2020_004) and by MH CZ - DRO (University Hospital Olomouc, 00098892 and Palacký University in Olomouc, 61989592).

\section{Conflict of Interests}

None declared

\section{REFERENCES}

1. World Health Organization. Asbestos: elimination of asbestos-related diseases [Internet]. Geneva: WHO; 2018 [cited 2020 Apr 14]. Available from: https://www.who.int/en/news-room/fact-sheets/detail/asbestoselimination-of-asbestos-related-diseases.

2. IARC Working Group on the Evaluation of Carcinogenic Risks to Humans. Overall evaluations of carcinogenicity: an updating of IARC Monographs volumes 1 to 42. IARC Monogr Eval Carcinog Risks Hum. 1987;Suppl 7:1-440.

3. International Labour Organization. Resolution concerning asbestos, 2006 [Internet]. Geneva: ILO; 2006 [cited 2020 Apr 14]. Available from: https:// www.ilo.org/safework/info/standards-and-instruments/WCMS_108556/ lang--en/index.htm.

4. Furuya S, Chimed-Ochir O, Takahashi K, David A, Takala J. Global asbestos disaster. Int J Environ Res Public Health. 2018 May 16;15(5):1000. doi: 10.3390/ijerph15051000.

5. Abós-Herràndiz R, Rodriguez-Blanco T, Garcia-Allas I, Rosell-Murphy IM, Albertí-Casas C, Tarrés J, et al. Risk factors of mortality from all asbestos-related diseases: a competing risk analysis. Can Respir J. 2017;2017:9015914. doi: 10.1155/2017/9015914.

6. International Ban Asbestos Secretariat. Current Asbestos Bans [Internet]. IBAS; 2019 [cited 2020 Apr 14]. Available from: http://www.ibasecretariat.org/lka_alpha_asb_ban_280704.php.

7. Ogunseitan $\mathrm{OA}$. The asbestos paradox: global gaps in the translational science of disease prevention. Bull World Health Organ. 2015 May 1;93(5):359-60.

8. Neumann V, Löseke S, Nowak D, Herth FJ, Tannapfel A. Malignant pleural mesothelioma: incidence, etiology, diagnosis, treatment, and occupational health. Dtsch Arztebl Int. 2013;110(18):319-26.

9. Attanoos RL, Churg A, Galateau-Salle F, Gibbs AR, Roggli VL. Malignant mesothelioma and its non-asbestos causes. Arch Pathol Lab Med. 2018;142(6):753-60.

10. Marsh GM, Riordan AS, Keeton KA, Benson SM. Non-occupational exposure to asbestos and risk of pleural mesothelioma: review and metaanalysis. Occup Environ Med. 2017;74(11):838-46. 
11. Government Decree No. 168 of August 6, 2014, amending Decree No. $290 / 1995$ Dig., wherein is set the list of occupational diseases in the wording of Decree No. 114/2011 Dig. Sbírka zákonů ČR. 2014 Aug 18; Pt 70:1853. (In Czech)

12. Act No. 46 on remuneration of occupational diseases of March 5, 1947. Sbírka zákonů ČR. 1947 Apr 4;Pt 23:349-52. (In Czech.)

13. Government Order No 290/1995. Laws For People [Internet]. [cited 2020 Apr 14]. Available from: https://www.zakonyprolidi.cz/cs/1995-290/ zneni-0. (In Czech.)

14. Government Decree No. 114 of April 6, 2011, amending Decree No. 290/1995 Dig., whereby is set the list of occupational diseases. Sbírka zákonů ČR. 2011 Apr 27;Pt 42:1090-6. (In Czech.)

15. World Health Organization. Outline for the development of national programmes for elimination of asbestos-related diseases [Internet]. Geneva: WHO; 2007 [cited 2020 Apr 14]. Available from: https://www.who.int/ occupational health/publications/asbestosdoc/en/.

16. National Institute of Public Health. Occupational diseases in the Czech Republic [Internet]. Prague: NIPH [cited 2020 Apr 14]. Available from: http://www.szu.cz/publikace/data/nemoci-z-povolani-a-ohrozeni-nemociz-povolani-v-ceske-republice?highlightWords=nzp. (In Czech.)

17. Institute of Health Information and Statistics of the Czech Republic. National Cancer Registry. Neoplasms [Internet]. Prague: IHIS CR [cited 2020 Apr 14]. Available from: https://www.uzis.cz/index.php?pg=registry-sberdat--narodni-zdravotni-registry--narodni-onkologicky-registr\#publikace. (In Czech, English.)

18. Dušek L, Mužík J, Kubásek M, Koptíková J, Žaloudík J, Vyzula R. Epidemiology of malignant tumors in the Czech Republic [Internet]. Brno: Masaryk University [cited 2020 Apr 14]. Available from: https://www. svod.cz/. (In Czech.)

19. Swiatkowska B, Szeszenia-Dabrowska N. Long-term epidemiological observation of asbestos-related diseases in Poland, 1970-2015. Occup Med (Lond). 2017;67(3):182-7.
20. Pelclová D, Fenclová Z, Urban P. Asbestos exposure, legislation and diseases in the Czech Republic. Cent Eur J Public Health. 2007;15(3):99102.

21. Pelclova D, Fenclova Z, Urban P. Occupational cancer in the Czech Republic - a tip of the iceberg? Eur J Oncol. 2011;16:149-61.

22. Lehnert M, Kraywinkel K, Heinze E, Wiethege T, Johnen G, Fiebig J, et al. Incidence of malignant mesothelioma in Germany 2009-2013. Cancer Causes Control. 2017 Feb;28(2):97-105.

23. Gogou E, Hatzoglou C, Zarogiannis SG, Malli F, Jagirdar RM, Gourgoulianis KI. Mesothelioma mortality rates in Greece for the period 2005-2015 is increased compared to previous decades. Medicina (Kaunas). 2019;55(8):419. doi: 10.3390/medicina55080419.

24. Garabrant DH, Pastula ST. A comparison of asbestos fiber potency and elongate mineral particle (EMP) potency for mesothelioma in humans. Toxicol Appl Pharmacol. 2018;361:127-36.

25. Marinaccio A, Binazzi A, Cauzillo G, Cavone D, Zotti RD, Ferrante P, et al.; Italian Mesothelioma Register (ReNaM) Working Group. Analysis of latency time and its determinants in asbestos related malignant mesothelioma cases of the Italian register. Eur J Cancer. 2007 Dec;43(18):2722-8.

26. Hilliard AK, Lovett JK, McGavin CR. The rise and fall in incidence of malignant mesothelioma from a British Naval Dockyard, 1979-1999. Occup Med (Lond). 2003;53(3):209-12.

27. Bianchi C, Bianchi T. Malignant mesothelioma: global incidence and relationship with asbestos. Ind Health. 2007;45(3):379-87.

28. Marinaccio A, Binazzi A, Cauzillo G, Chellini E, De Zotti R, Gennaro $\mathrm{V}$, et al.; Gruppo di lavoro ReNaM. Epidemiological surveillance of malignant mesothelioma cases in Italy: incidence and asbestos exposure figures by the Italian mesothelioma registry $(\mathrm{ReNaM})]$. Epidemiol Prev. 2007 Jul-Aug;31(4 Suppl 1):23-6. (In Italian.)

Received May 18, 2020 Accepted in revised form August 2, 2020 